\title{
Current Challenges in Delivery and Cytosolic Translocation of Therapeutic RNAs
}

\author{
Ludger Johannes and Marco Lucchino
}

RNA interference (RNAi) is a fundamental cellular process for the posttranscriptional regulation of gene expression. RNAi can exogenously be modulated by small RNA oligonucleotides, such as microRNAs (miRNAs) and small interfering RNAs (siRNAs), or by antisense oligonucleotides. These small oligonucleotides provided the scientific community with powerful and versatile tools to turn off the expression of genes of interest, and hold out the promise of new therapeutic solutions against a wide range of gene-associated pathologies. However, unmodified nucleic acids are highly instable in biological systems, and their weak interaction with plasma proteins confers an unfavorable pharmacokinetics. In this review, we first provide an overview of the most efficient chemical strategies that, over the past 30 years, have been used to significantly improve the therapeutic potential of oligonucleotides. Oligonucleotides targeting and delivery technologies are then presented, including covalent conjugates between oligonucleotides and targeting ligand, and noncovalent association with lipid or polymer nanoparticles. Finally, we specifically focus on the endosomal escape step, which represents a major stumbling block for the effective use of oligonucleotides as therapeutic agents. The need for approaches to quantitatively measure endosomal escape and cytosolic arrival of biomolecules is discussed in the context of the development of efficient oligonucleotide targeting and delivery vectors.

Keywords: oligonucleotides, miRNA, siRNA, Shiga toxin B-subunit, immunotherapy, checkpoint inhibitor

\section{Introduction}

G ROUNDBREAKING DISCOVERIES of the past 20 years revealed that RNA molecules not only serve as carriers of genetic information, but also have central roles in regulating gene expression. Indeed, noncoding RNAs intervene in a multitude of cellular functions [1]. RNA molecules, such as double-stranded small interfering RNAs (siRNAs) and microRNAs (miRNAs), are able to trigger RNA interference (RNAi). RNAi represents a fundamental cellular process used for the posttranscriptional regulation of gene expressions [2], and as defense mechanism against foreign RNA molecules (eg, viral double-stranded RNA) [3]. Interestingly, RNAi provided the scientific community with a powerful and versatile tool to turn off individual genes. miRNAs, synthetic siRNAs, and antisense oligonucleotides (ASOs) have in common a great therapeutic potential for a wide range of diseases, since genes and related products now represent druggable targets [4].

Human cells express more than 400 different miRNAs, which are involved in the regulation of at least one-third of all human protein-coding genes. Biogenesis of miRNA starts in the nucleus, where RNA polymerase II transcribes miRNA genes into primary miRNAs (pri-miRNAs). Complementarity in pri-miRNAs sequences confers to these single-stranded molecules a hairpin structure that is capped at the $5^{\prime}$ end, and polyadenylated at the $3^{\prime}$ end. pri-miRNAs maturation starts in the nucleus, where cropping occurs at specific sites, followed by export to the cytosol [5].

miRNA precursors are cleaved in the cytosol by the Dicer enzyme to form a proper double-stranded miRNA of $22 \mathrm{bp}$ in length. Mature miRNA is then loaded onto the RNA-induced silencing complex (RISC). One of the RISC proteins, Argonaute, cleaves and thereby discards one of the miRNA strands, whereas the remaining single-stranded (antisense) molecule serves as guide for RISC to recognize and bind target messenger RNAs (mRNAs) [6]. Depending on the extent of base pairing with the RISC/miRNA complex, mRNAs can either be cleaved by the Argonaute protein and degraded by endonucleases, or moved to a cytosolic structure called processing bodies (P-bodies), where RNA-degrading enzymes proceed with mRNA destruction [7]. Following degradation of the mRNA, the RISC, still associated with the guide-strand miRNA, can seek for further mRNAs and catalyze their degradation.

siRNAs are double-stranded RNA molecules that typically are 19-23 nucleotides in length. Once in the cytosol, siRNAs directly associate with the RISC machinery. Similarly to miRNAs, one strand is cleaved by the Argonaute protein, whereas the other one serves as RISC guide strand [8].

Institut Curie, PSL Research University, Cellular and Chemical Biology, U1143 INSERM, UMR3666 CNRS, Paris, France.

(c) Ludger Johannes and Marco Lucchino, 2018; Published by Mary Ann Liebert, Inc. This Open Access article is distributed under the terms of the Creative Commons Attribution Noncommercial License (http://creativecommons.org/licenses/by-nc/4.0/) which permits any noncommercial use, distribution, and reproduction in any medium, provided the original author(s) and the source are cited. 
ASOs have also been extensively studied as potential therapeutic agents. ASOs are single-stranded oligonucleotides, typically $20 \mathrm{bp}$ in length that promote degradation of complementary mRNA by engaging ribonuclease $\mathrm{H}$ (RNase H) enzymes [9]. RNase H hydrolyzes the RNA in RNA/DNA heteroduplexes [10]. Similar to the catalytic mechanism triggered by siRNAs and miRNAs, ASOs are released after mRNA degradation, and induce the degradation of further mRNA molecules. ASOs can also arrest ribosomal activity by steric hindrance, or interfere with mRNA maturation [11].

High specificity, potency, versatility, and design simplicity hold out the promise to transform small oligonucleotide molecules into therapeutic solutions against gene-associated pathologies, from cancer to autoimmune diseases, genetic disorder, and viral infections. However, unmodified nucleic acids are highly instable molecules in biological systems by being exposed to ubiquitous nucleases. Furthermore, small size and negative charge result in weak interaction with plasma proteins and in fast kidney excretion, leading to unfavorable pharmacokinetics. This represents a major hurdle for unmodified nucleic acids to reach their molecular targets, and therefore to be used as systemic drugs.

In this review, we first provide an overview of the most efficient chemical strategies that, over the past 30 years, have been used to significantly improve the therapeutic potential of oligonucleotides, yielding nuclease-resistant oligoRNAs with increased plasma stability and favorable pharmacokinetic profiles. Oligonucleotide targeting and delivery technologies are then presented, including covalent conjugates between oligonucleotides and targeting ligand, and noncovalent association with lipid or polymer nanoparticles. Finally, we specifically focus on the endosomal escape step, which represents the major stumbling block for the effective use of oligonucleotides as therapeutic agents. The need for efficient approaches to quantitatively measure endosomal escape and cytosolic arrival of biomolecules is discussed in the context of the development of efficient oligonucleotide targeting and delivery vectors.

This review does not cover replicative oligonucleotide delivery technologies such as viruses, bacteria, and bacteriophages. The reader is referred to recent reviews on these approaches [12-15].

\section{Chemical Modifications}

Chemical modification of the nucleotides' backbone increased its stability toward nucleases, while maintaining, or even improving, affinity and specificity for target RNAs. This resulted in more favorable pharmacodynamics and pharmacokinetic profiles for oligonucleotide therapeutics. New classes of chemically modified oligonucleotide also afforded reduced immunostimulatory signaling, thereby decreasing off-target effects and increasing circulation time. Such longer half-life in circulation is directly related to a stronger interaction with plasma proteins. Excellent recent reviews [16-18] provide a detailed description of chemical nucleotide modifications. In this section, we will therefore limit our discussion on the main chemically synthesized nucleic acids, and the most common modifications of the RNA backbone (Fig. 1a).

\section{Phosphorothioate}

Because of its instability toward nucleases, the phosphodiester bond has been one of the most modified linkages within the oligonucleotide backbone. The first successful modification, which to date is still the one that is used most often, consisted in the replacement of one of the nonbridging oxygen atoms of the phosphate group with a sulfur atom, thereby generating a phosphorothioate (PS) bond (Fig. 1b). The sulfur atom confers to PS oligonucleotides an excellent resistance toward nucleases [19], and favorable pharmacokinetic profiles. Indeed, sulfur atoms increase the hydrophobicity of the nucleotide backbone, leading to an increased interaction with plasma proteins. This modification, together with the 2-O' sugar modification, has been extensively used in the development of new therapeutic ASOs $[11,20]$. Besides the improved stability and the longer circulation time, PS-ASOs remain substrates for RNase $\mathrm{H}$ and, even more importantly, enhanced hydrophobicity favors membrane translocation to the cytosol to reach mRNA targets [21-23]. The mechanisms by which the plasma membrane (or internal membranes) is crossed remain poorly understood. The capacity of membrane translocation has represented a key advantage for PS-ASOs' development, as no delivery/transfection agents are required [21].

The PS modification has also been used extensively in the design and synthesis of nuclease-resistant siRNAs. However, full PS modification of siRNAs reduces their silencing effect, whereas partially substituted siRNAs retain silencing activity $[24,25]$. The reduced silencing activity of fully PS-modified siRNAs is probably a consequence of an alteration of the double-stranded A-form structure. In fact, the A-form's major groove in siRNA-mRNA duplexes is essential for RISC recognition and activation, and its alteration affects the RNAi machinery. PS modification is better tolerated at the ends of the strands, leaving the major groove unaltered [26].

\section{$2 \mathrm{OH}^{\prime}$ modification}

Changes in the ribose $2^{\prime} \mathrm{OH}$ group are generally well tolerated by the RNAi machinery. In fact, this hydroxyl group is not involved in the catalytic activity of RISC [26]. The 2'-O$\mathrm{Me}, 2^{\prime}-\mathrm{F}$, and 2'-O-(2-methoxyethyl) (MOE) represent the most commonly used ribose modifications (Fig. 1c). In particular, the biophysical propriety of $2^{\prime}-\mathrm{O}-\mathrm{Me}$ and $2^{\prime}-\mathrm{F}$ groups are similar to the ribose $2^{\prime} \mathrm{OH}$ group, which allows to preserve the siRNA A-form, or at least a RNA-like conformation. Indeed, these modifications confer excellent stability toward nucleases [27], and prevent the activation of the immune system $[3,16,28]$. It must be taken in account that the $2^{\prime}$ modification can lead to a shift in terms of RNAi activity [24]. Furthermore, extensive studies have been performed to understand how 2'OH modification influences RNAi activity while improving endonuclease resistance [29,30]. The trick appears to be to find the right siRNA sequence for a given gene in combination with the best $2^{\prime}$ modification pattern to induce a long-lasting silencing effect, while increasing RNA stability [31]. siRNA design often relies on the use of rational algorithms followed by alignment studies and gene expression analysis to ensure target specificity [31,32]. Fully 2 '-modified siRNAs have been shown to retain RNAi activity and long duration of RNAi responses, when compared with unmodified siRNA [33,34]. Indeed, most of the therapeutic siRNA currently in clinical trials contain $2^{\prime} \mathrm{F}$ and $2^{\prime} \mathrm{OMe}$ modifications $[35,36]$. Several ASO bearing $2^{\prime}$ modification have also entered clinical trials [37-39], and two drugs, Mipomersen [40] and Nusinersen [41], have received FDA approval [20]. 

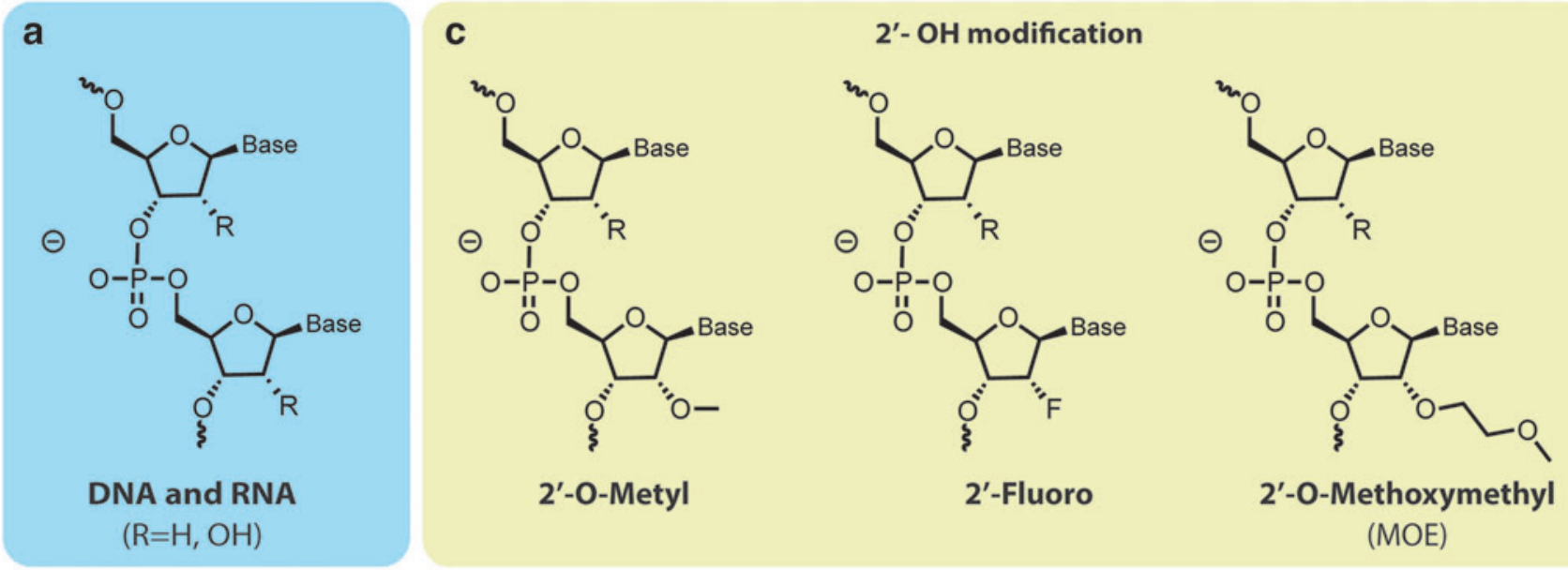

b

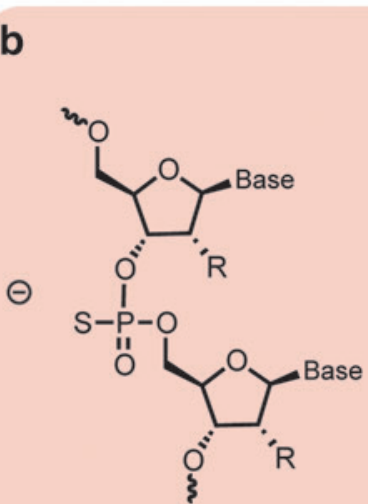

Phosphorothioate

(PS)

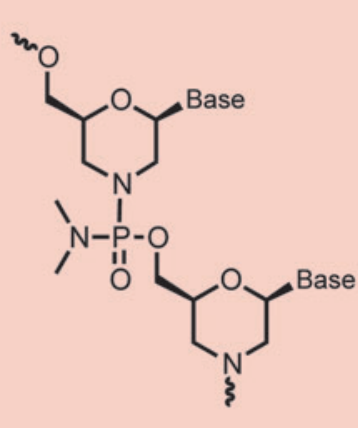

Morpholino

(PMO)

Backbone modification

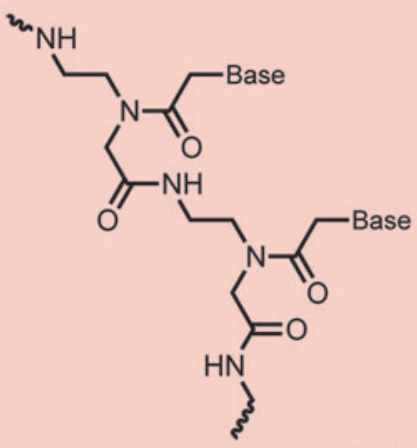

Peptide Nucleic Acid

(PNA)

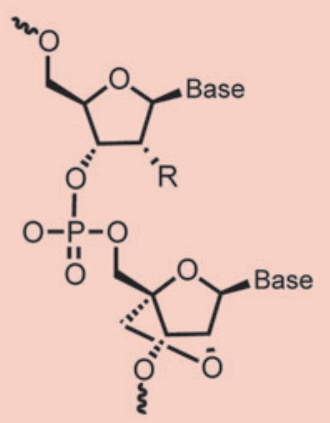

Locked Nucleic Acid (LNA)

FIG. 1. Modifications of native RNA structure (a) have been developed to improve oligonucleotide stability and their drug-like properties. (b) Phosphorothioate was the first group used as a bioisosteric replacement of the phosphodiester backbone. Many other stable chemical groups, such as phosphorodiamidate morpholino oligonucleotides, peptidic nucleic acids, and locked nucleic acids have since been developed. (c) The majority of modifications involve changes at the 2'-OH position. 2'-O-Me, 2'-F and 2'-O-(2-methoxyethyl) (MOE) represent the most commonly used ribose modifications.

\section{Other modifications}

Many other nucleotide modifications have been explored for the development of therapeutic ASOs, in addition to PS and 2 '-OH. Indeed, locked nucleic acids (LNAs), often referred as inaccessible RNAs, are nowadays widely used. Their main advantages are stability against nucleases, and increased oligonucleotide hybridization and binding properties [42]. In LNAs, the $2^{\prime}$ oxygen is covalently bridged to the $4^{\prime}$ carbon (Fig. 1b). This confers a locked conformation to the molecule [43], which results in enhanced base stacking and backbone preorganization. The phosphorodiamidate morpholino oligonucleotide (PMO) and peptide nucleic acid (PNA) modifications exhibit high stability toward nucleases, and provide an uncharged backbone [44] (Fig. 1b). The constrained structure of PMO and low electrostatic repulsion result in an improved interaction between synthetic oligoRNAs and target mRNA, even when compared with the DNA/RNA interaction [45]. The sugar rings in PMOs are replaced by morpholino rings linked to each other through a phosphorodiamidate bond. Eteplirsen is a 30-nucleotide phosphorodiamidate morpholino oligomer, neutrally charged at physiological $\mathrm{pH}$ that has been the first FDA-approved drug for Duchenne muscular dystrophy (DMD). DMD is a fatal neuromuscular disorder characterized by progressive muscular deterioration due to a loss-of-function mutation in the gene coding for dystrophin. Eteplirsen promotes dystrophin production by restoring its translation reading frame through specific skipping of exon 51 in defective gene variants [46]. However, even if the FDA granted an accelerated approval for eteplirsen, its efficacy still remains controversial.

In PNAs, the sugar backbone is entirely replaced by repeated N-(2-aminoethyl)-glycine bridges linked to each other by amide bonds [17]. Even if PNAs are a radically different class of oligonucleotides, they still maintain the ability to Watson-Crick base pair with complementary RNA and DNA [47]. However, both PMOs and PNAs do not support RNase $\mathrm{H}$ activity [27,47].

Throughout the last decade, the phosphodiester bond has successfully been replaced by amides [48,49], hydroxylamines [50], and acetals [51], preserving good binding affinity and stability. However, better results as those obtained with the PS backbone have not yet been achieved. 


\section{Delivery Issues}

Chemical modification of ASOs has afforded significant improvements in terms of nucleases stability, low immunogenicity, increased efficiency of base pairing, and reduced off-target activity. However, to exploit the full potential of oligonucleotide-based therapeutics, some additional difficulties have to be overcome. In fact, ASOs and siRNAs are large and highly negatively charged biomolecules, with suboptimal bioavailability, and in most cases, an ineffective delivery onto target cells. In the context of a systemic administration of oligonucleotide-based drugs, many biological hurdles have to be overcome, ranging from vascular impediments to internalization into target cells and endosomal escape to the cytosolic compartment.

Vascular endothelial cells are strongly tied together by adherence and tight junctions, forming a highly regulated barrier between blood and surrounding tissues. Passing this vascular barrier for therapeutic purposes through paracellular or transcellular transport routes remains highly challenging [52]. In some organs, such as liver and spleen, and in particular pathological condition, such as inflammation and certain types of cancer, endothelial fenestrations are large enough to allow egress of oligonucleotides or nanoparticles [53]. In fact, for nontargeted siRNAs or nanoparticles, liver and kidney have been shown to be the major accumulation sites [54,55]. Therefore, it is not surprising that many siRNAs and miRNAs $N$-acetyl galactosamine (GalNAc) conjugates and nanoparticles that have entered the clinics have been developed to treat liver-associated disease (see Sehgal et al. [56]).

Internalization into cells by endocytosis and translocation to the cytosol further constitute major problems encountered in the development of RNA drugs. Indeed, because of their polyanionic nature, RNA oligomers are not able to spontaneously cross cellular membranes. They often remain trapped in endosomal compartments, leading to lysosomal degradation or recycling to the plasma membrane [21,57].

These problems represent important obstacles for the development of RNA scaffolds as a new class of therapeutics. Indeed, still only a limited number of RNA-based formulations have advanced to clinical testing, despite numerous preclinical reports on the optimization and development of novel tools for oligonucleotide delivery. Hereafter, the main technologies for RNA delivery are presented.

\section{Cationic peptides}

The capacity to interact and condensate negatively charged RNAs, the ease by which they can be synthesized, and their tunable physicochemical properties have made cationic peptides a widely used carrier for oligonucleotides [58]. Cationic peptides have been exploited in different approaches, such as direct conjugation to RNA strands, noncovalent complexation with negatively charged oligonucleotides, and use as adjuvants in polymeric or lipidic carriers [59].

However, many problems emerged with the use of polycation RNA complexes. Indeed, such formulations show poor long-term stability with the tendency to form aggregates. Apart from the loss in transfection efficiency, aggregation entails substantial hurdles that would impede manufacturing of marketable pharmaceutical products [60]. While in vitro experiments show promising results, the administration of cationic polymer- and peptide-based nanoparticles cause major adverse effects [61]. Lastly, high variability of freshly prepared injection solutions would represent an unacceptable risk for the patients. Therefore, the reader should be aware that aggregation and toxicity are two main concerns that still need to be addressed conclusively with the use of cationic peptides and proteins.

Poly(L-lysines). Poly(L-lysines) (PLLs) were one of the first oligonucleotide carriers [62]. Their polyamino acidic nature made PLLs an attractive biodegradable polymer for drug delivery purposes. The molecular weight of PLLs can vary from a few hundreds of $\mathrm{Da}$ to more than $100 \mathrm{kDa}$. However, PLLs have been shown to be toxic in vivo, and their toxicity increases with chain length. PLLs with a molecular weight between 2 and $30 \mathrm{kDa}$ have been preferably used for siRNA and DNA delivery $[58,63]$. Poly-lysine polymers themselves do not exhibit any particular transfection capacity and are susceptible to proteolytic degradation, opsonization, and rapidly excretion through kidneys [64]. To overcome these limitations and to improve their delivery capacity and halflife, PLLs have been extensively functionalized throughout the years. Conjugation with endosomal-disrupting agents and fusogenic peptides to promote endosomal escape and cytosolic arrival was among the most important modifications [59]. Polyethylene glycol (PEG) functionalization has been widely exploited to reduce opsonization and kidney filtration, thus extending circulation time [65]. Furthermore, PLL nanoparticles are disassembled in serum, thereby limiting the gene silencing efficacy of corresponding siRNA complexes.

Protamine. Protamines are a family of arginine-rich proteins involved in spermatid genome condensation in many animal and plant cells [66]. Taking advantage of this natural function, protamines have been extensively used for oligonucleotide delivery. Native protamine has been exploited to condense long mRNA molecules into nanoparticle complexes [67], and for the delivery of small RNAs. For instance, cyclin D1(CyD1), a cell cycle-regulating protein that governs proliferation of normal and malignant cells, has been significantly depleted in cells and mice using protaminecondensed CyD1 siRNAs that were efficiently incorporated in 37-integrin targeting liposomes (Table 1) [68]. In another study, protamine has been used to condense a multicomponent siRNA-biotin-streptavidin complex to produce small nanoparticles characterized by efficient cellular uptake [69].

Probably the most innovative and most widely used approach concerns antibody-protamine fusion proteins that exploit antibody-mediated targeted delivery. Many groups over the past few years have successfully produced antibody-protamine fusion protein to complex siRNA and to specifically downregulate protein expression in target cell lines or organs (Fig. 2a). For instance, HIV-1 envelope protein expression was significantly reduced in HIV-infected cells using a protamine-Fab fragment fusion protein complexed with antigag siRNA (Table 1) [70]. Similarly, antibody-recognition of prostate-specific membrane antigen (PSMA), a cell surface glycoprotein mainly expressed on prostate cancer cells, has been exploited to selectively deliver protamine-complexed siRNAs against Notch1. The Notch pathway is involved in several cellular processes. Its abnormal activation has been observed in many cancers, including prostate cancer [71]. Targeted delivery of siNotch1 was successfully achieved in 
Table 1. Targeted Oligonucleotide Systems: Targeting Ligands Are Paired with Oligonucleotide Formulations to AfFord Specific Gene Silencing

\begin{tabular}{|c|c|c|c|c|}
\hline Targeting moiety & Formulation & Diseaselapplication & Targeted gene & References \\
\hline $\begin{array}{l}\text { Monoclonal antibody } \\
\text { against } \beta 7 \text { integrin }\end{array}$ & $\begin{array}{l}\text { Liposome containing } \\
\text { protamine-condensed siRNA }\end{array}$ & Inflammation & CyD1 & [68] \\
\hline $\begin{array}{l}\text { Fab fragment of an HIV-1 } \\
\text { envelope antibody }\end{array}$ & $\begin{array}{l}\text { siRNA condensed to antibody- } \\
\text { protamine fusion protein }\end{array}$ & HIV & gag & [70] \\
\hline Anti-PSMA antibody & $\begin{array}{l}\text { siRNA condensed to antibody- } \\
\text { protamine fusion protein }\end{array}$ & Cancer & Notch1 & [72] \\
\hline $\begin{array}{l}\text { Single-chain antibody } \\
\text { against DEC205 }\end{array}$ & $\begin{array}{l}\text { siRNA encapsulated within lipid } \\
\text { nanoparticles }\end{array}$ & Immunosuppression & $\begin{array}{l}\text { CD40, CD80, } \\
\text { CD86 }\end{array}$ & [119] \\
\hline Folic acid & DNA nanoparticles & Cancer & $\begin{array}{l}\text { Luciferase } \\
\text { assay }\end{array}$ & [111] \\
\hline Folic acid & PEI nanoparticles containing siRNA & Cancer & VEGF & [123] \\
\hline Apolipoprotein E & $\begin{array}{l}\text { siRNA encapsulated within lipid } \\
\text { nanoparticles }\end{array}$ & Amyloidosis & Transthyretin & [108] \\
\hline RGD & SSO conjugate & Cancer & $\begin{array}{l}\text { Luciferase } \\
\text { assay }\end{array}$ & [127] \\
\hline RGD & $\begin{array}{l}\text { Chitosan nanoparticles containing } \\
\text { siRNA }\end{array}$ & Cancer & Periostin & [128] \\
\hline Cyclo RGD & siRNA conjugate & Cancer & VEGFR2 & [129] \\
\hline GalNAc & siRNA conjugate & $\begin{array}{l}\text { Amyloidotic, } \\
\text { cardiomyopathy }\end{array}$ & TTR & [130] \\
\hline GalNAc & siRNA conjugate & $\beta$-Thalassemia & Tmprss6 & [130] \\
\hline Aptamer against PMSA & siRNA chimera & Cancer & PLK1 & [133] \\
\hline Aptamer against gp120 & siRNA chimera & HIV & HIV RNAs & [134] \\
\hline
\end{tabular}

GalNAc, $N$-acetyl galactosamine; PEI, poly(ethylenimine); PLK1, polo-like kinase 1; PSMA, prostate-specific membrane antigen; RGD, arginine-glycine-aspartate; siRNA, small interfering RNA; SSO, splice-shifting oligonucleotide; TTR, transthyretin; VEGF, vascular endothelial growth factor.

the LNCaP prostate cancer cell line. Notch1 downregulation led to cell cycle arrest and apoptosis (Table 1) [72].

Another group has taken advantage of the epidermal growth factor receptor family member ErbB2 (HER2), which is overexpressed in Her2+ breast cancers to deliver polo-like kinase 1 (PLK1) siRNAs, both in primary Her2+ breast cancer cells, and in xenograft models [73]. Selective and efficient siRNA delivery led to the depletion of the targeted genes, resulting in reduced cell proliferation and the induction of apoptosis.

Many other studies confirmed the potential of protamineantibody fusions as delivery tools for nucleic acids [74]. Interestingly, siRNA conjugates with unmodified antibodies showed lower cellular uptake compared with siRNAs that were complexed with protamine-antibody fusion proteins [70]. It is likely that the charge balance between positively charged protamine and negatively charged siRNAs favors internalization and endosomal escape.

Protamine has been widely used for siRNA delivery and other biomedical applications [75,76], despite the fact that cardiovascular and respiratory toxicity and adverse immune reactions were observed after intravenous injection [77]. To decrease toxicity, low-molecular-weight protamines (LMWPs) have been developed [78,79]. LMWPs are produced through enzymatic digestion of the native protamine with thermolysin. They contain short sequences of about $2 \mathrm{kDa}$ that are enriched in arginine. LMWP are poorly immunogenic and do not cause hypotensive or toxic responses [77,80]. LMWPs have been successfully used for siRNA delivery [80,81]. Choi et al. showed that a stable LMWP/siRNA complex was efficiently taken up by hepatocarcinoma cells. Significant downregulation of the targeted vascular endothelial growth factor (VEGF) led to cell growth inhibition and apoptosis. Experiments in mice confirmed the therapeutic potential of this formulation [80]. Because of their peptidic nature and physicochemical similarity, LMWPs are often considered as cell-penetrating peptides (CPPs).

Cell-penetrating peptides. CPPs are peptides of 5-30 amino acids in length, often positively charged that are capable of passing through tissue barriers and cell membranes without interacting with any specific receptor [82]. CPPs are internalized by endocytosis, or translocated by passive diffusion directly across the plasma membrane. Endocytic uptake may ultimately also favor membrane translocation to the cytosol. The molecular details of processes by which the lipid bilayer is breached are not yet fully established [83].

The transactivator of transcription (TAT) and penetratine were the first CPPs to be described. It has then been shown that CPPs are capable of transporting a variety of biologically active payloads, such as peptides, proteins, and oligonucleotides inside cells [84]. siRNAs can either be covalently conjugated to CPPs, or noncovalently associated with CPPs through electrostatic interactions, yielding complexes or nanoparticles [27]. For instance, Endo-Porter is an amphipathic CPP that was shown to be capable of delivering noncovalently bound siRNAs [85] and morpholino-RNAs [86] through an energy-independent mechanism into cells. Covalent conjugation of CPPs with small oligo-RNAs affords a well-defined macro-biomolecule with a one-to-one CPP/siRNA ratio that is stable in circulation. Such well-defined molecular entity facilitates the drug development process [45].

The direct conjugation of siRNAs to CPP may result in neutralizing the charges on CPPs, which would lead to a 
a

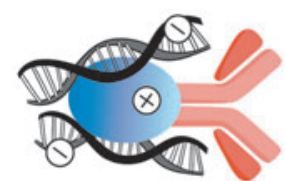

Protamine-antibody siRNA complex

b

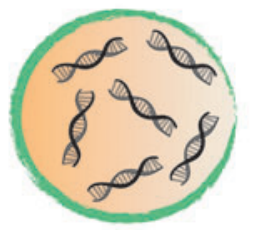

Targeted and untargeted polymeric nanoparticles
C

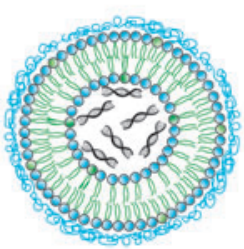

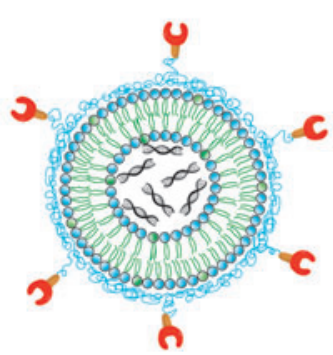

Targeted and untargeted PEGylated lipid vehicles d

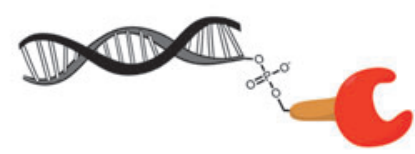

Targeted oligonucleotide conjugates

e

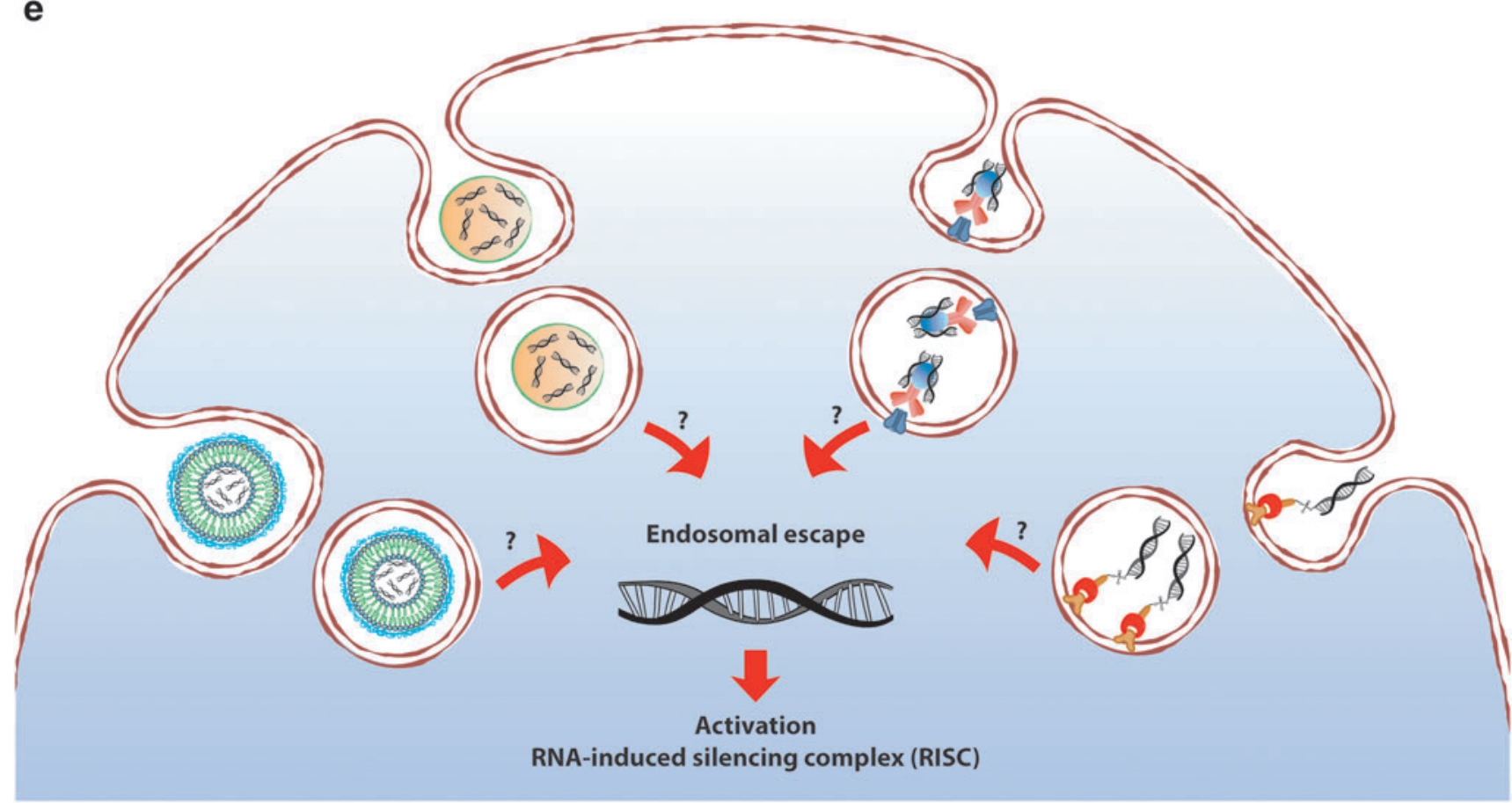

FIG. 2. Common modalities for oligonucleotide delivery. (a) Protamine-antibody fusion protein complexed with oligoRNAs. (b) Example of polymeric nanoparticles containing siRNA molecules. (c) Schematic illustration of PEGylated lipidic nanoparticles comprising siRNA. (d) Direct conjugation of siRNAs with a targeting ligand. (e) Despite great progress in vector development, most of internalized molecules accumulate in endosomes. Only a small fraction reaches the cytosol, where the RISC machinery is located. The mechanisms of endosomal escape still remain poorly understood. PEG, polyethylene glycol; RISC, RNA-induced silencing complex; siRNA, small interfering RNA.

reduced efficiency of membrane translocation [58]. To circumvent this problem, nucleic acid analogs with reduced charges, such as PNA and PMO, have been used in conjugation with CPPs [87,88]. In studies on cells in culture and on animals, such as mice and nonhuman primates, it was shown that conjugation to CPPs much improved the cellular uptake and efficiency of PMOs for the treatment of DMD $[89,90]$. Systemic injection of a cocktail of CPP-conjugated PMOs rescued muscular dystrophin expression in canine model of DMD [91]. Leaky muscle fibers and weakened muscular cell 
membranes that are characteristic of muscular dystrophies likely favor cellular uptake and translocation of PMOs into the cytosol [92].

Nanoparticles. Incorporation into nanoparticles or nanocapsules is another popular strategy to protect oligonucleotides from degradation, to assist their delivery onto target cells, and to promote their cellular uptake and subsequent endosomal escape, the latter probably being the biggest challenge for the development of oligonucleotide-based therapeutics [18].

Polymeric nanoparticles. Because of their tunable chemical properties, polymers are among the most common materials that are used in nanoparticle production, followed by lipids and lipid-like materials (Fig. 2b). Since they need to condense nucleic acids, cationic polymers are preferred over neutral or negatively charged ones. Next to PLL, poly(ethylenimine) (PEI) represents another well-explored polymer for RNA delivery [12]. Besides its nucleic acid condensation properties, the many protonable secondary amines of PEI likely promote endosomal escape through the proton-sponge effect [16]. According to this hypothesis, the high proton buffering capacity of PEI would lead to high osmotic pressure within organelles of the endocytic pathway, thereby causing the rupture of endosomes and/or lysosomes, and release of oligonucleotides to the cytosol [93]. However, this mechanistic proposal has recently been called into question, and it even seems unclear whether this proton sponge effect actually exists [94].

The molecular weight of PEI is critical to balance toxicity and transfection efficiency of PEI/siRNA complexes. Yet, apparently conflicting results have been reported concerning the transfection capacity of PEI in function of the molecular weight and polymer branching [95]. It seems clear, however, that even though low molecular weight confers to PEI a more favorable toxicological profile [12], transfection efficacy of PEI is strongly correlated with cytotoxicity. Indeed, because of this toxicity, PEI is now largely excluded as delivery tool for RNAs. Other polymers such as poly(amidoamine) (PAMAM) [96] and the natural chitosan [97] have also been used with variable levels of success for siRNA delivery.

Lipid nanoparticles. Lipid nanoparticles (LNPs) represent probably the most popular approach for siRNA delivery (Fig. 2c). Of note, LNP-siRNA complexes are already used in clinical trials $[98,99]$, and are about to become the first FDA-approved siRNA drug. Synthesis of LNPs for oligonucleotide delivery usually involves four to five components, always including cationic lipids, which promote RNA packing and nanoparticle formation, and cholesterol as a stabilizing agent [99]. Simple LNPs represent an efficient cell culture transfection agent. In vivo, they are rapidly opsonized, however, and cleared by phagocytic cells of the reticuloendothelial system (RES) [100]. To overcome this problem and to prolong their circulation half-life, LNP surfaces are often coated with PEG. The hydrophilic and flexible PEG chains form a protecting shell around the nanoparticles, thereby preventing their interaction with opsonins and RES activation (stealth effect) $[1,101,102]$. LNPs are $100-200 \mathrm{~nm}$ in size and, upon systemic administration, can extravasate only at sites where the endothelium is fenestrated. By taking advantage of the discontinuous and highly permeable hepatic vasculature, LNPs represent one of the main options to target liver disease [103]. Alnylam Pharmaceuticals has successfully completed a Phase 1 clinical trial with ALN-VSP LNPs to treat advanced cancer with hepatic metastasis [104]. ALNVSP comprises two siRNAs that target VEGF, which is critical for the growth of new blood vessels [105], and kinesin spindle protein (KSP), involved in cell division [106]. Upon parenteral administration, ALN-VSP passively accumulates in the liver, where it mediates anticancer activity. ALN-VSP is well tolerated. Interestingly, the formulation is also found in extrahepatic metastatic tumor biopsies. This is most likely due to a leaky vasculature and a lack of lymphatic drainage at cancer sites.

The passive accumulation of nanoparticles on cancerous tissue is known as the enhanced permeability and retention (EPR) effect, which is nowadays strongly debated. EPR occurs efficiently in subcutaneous tumor models in mice, whereas human tumors show a different growth environment and vasculature. The extent of EPR can notably vary among tumors, and from patient to patient. Indeed, tumor size, type and location, the composition of the extracellular matrix, vascular permeability, and tumor perfusion make of EPR a heterogeneous phenomenon that needs further investigation to effectively foster nanoparticle drug delivery [107]. As described above, the vascular architecture of the liver has been extensively exploited for nanoparticle delivery. A further improvement in hepatic delivery was achieved by coating the LNP surface with hepatocyte-targeting domains [1]. For instance, Patisiran is an LNP developed for the delivery of siRNAs that target transthyretin (TTR) mRNA. This LNP is in phase 3 clinical trials for the treatment of hereditary transthyretin-mediated amyloidosis (ATTR), which is a progressive, life-threatening disease. ATTR is caused by accumulation of misfolded TTR, predominantly produced in the liver [98]. To further promote liver uptake, the LNP surface of Patisiran is coated with apolipoprotein E (ApoE), which binds to the ApoE receptor that is overexpressed on hepatocytes and mediates LNP internalization (Table 1) [108]. In a previous phase 1 trial, a significant and durable TTR knockdown was achieved in the absence of serious adverse side effects [103].

DNA and RNA nanoparticles. DNA and RNA nanotechnology has exponentially grown in the past 20 years in recognition of its potential in the field of nanomedicine $[109,110]$. By exploiting the base-pairing capacity of DNA and RNA, nanostructures of different complexities, shapes, and dimensions can be obtained. Indeed, the ability to precisely control size and shape in one, two, or three dimensions makes DNA and RNA nanostructures attractive and unique tools with promising delivery capacity. Modular RNA or DNA building blocks can be connected using linkers and structural junction motifs, offering a plethora of new opportunities for the bottom-up assembly of drug delivery carriers [110]. Moreover, oligonucleotide strands can be programmed such as to functionalize nanoparticles with targeting moieties whose spatial orientations and densities are precisely controlled. An additional benefit in the use of oligonucleotidebased carriers comes from the possibility of hybridizing therapeutic RNAs onto them. For instance, DNA tetrahedron nanoparticles have been developed for siRNA delivery (Table 1) [111]. A specific DNA overhang design allowed 
incorporation of six 2'-OMe-modified siRNAs per nanoparticle, providing a homogeneous population of nanocarriers in terms of size and shape. Twenty-eight different ligands, from peptides to small molecules, have been conjugated to DNA nanoparticles. Cationic peptides caused nanoparticle aggregation, due to electronic interactions with negatively charged nucleotide strands, whereas folic acid conjugates afforded a dose-dependent gene-silencing effect in HeLa cells, and in xenografted mice.

RNA nanostructures are thermodynamically more stable than DNA nanostructures and possess high structural flexibility and versatility [112,113]. For instance, phi29 promoterassociated RNA (pRNA)-based vectors can be used as vehicles for siRNA delivery. To produce such RNA nanoparticles, chimeric RNA complexes were developed by fusing siRNAs with bacteriophage phi29 motor pRNA [109,110,114]. pRNAderived nanoparticles are small $(20-40 \mathrm{~nm})$ and homogenous in size. Furthermore, they can be functionalized with targetspecific ligands. For instance, a folate-conjugated pRNA construct has been developed for the delivery of siRNAs into folate receptor-overexpressing nasopharyngeal carcinoma cells. It was shown that the pRNA/siRNA fusion was successfully processed by Dicer, leading to specific suppression of gene expression [115].

\section{Targeting Strategies}

The remarkable advances over the last two decades in the development of ASO and siRNA vectors have not yet been accompanied by a comparable clinical success. A major limitation originates from the difficulty to deliver a therapeutic dose of oligonucleotides at the target site, particularly for extrahepatic tissues, such as cancers or immune cells. Therefore, as already introduced above, targeting oligonucleotides to specific cell types and organs appears to be of fundamental importance to enhance cellular uptake and to gain selective extrahepatic delivery. Cell specificity is achieved by combining therapeutic oligonucleotides with targeting ligands that bind receptors on the surface of target cells, and mediate internalization of conjugates (Fig. 2d).

Among the many available targeting ligands, antibodies have emerged as one of the most promising options [116]. However, following the initial excitement for oligonucleotideantibody conjugates, many difficulties have been encountered [3]. The main problems reside in antibody production and conjugate stability.

Antibody-siRNA conjugates have shown weak silencing capacity due to poor endosomal escape of these large $(180 \mathrm{kDa})$ and hydrophilic molecules [27,117]. Coating the surface of LNPs with antibodies also represents an important challenge. The main difficulty resides here in finding on optimal ratio for coating with PEG and antibody molecules, while maintaining efficient antibody-binding capacity and long circulation time [118]. Interestingly, the efficient targeting of dendritic cells was recently demonstrated, using LNPs coated with a single-chain variable fragments ( $\mathrm{scFv}$ ) (Table 1) [119]. An efficient siRNA-mediated knockdown of different costimulatory surface antigens was afforded on cells in culture, and in animals.

Other nonantibody targeting moieties have been explored for oligonucleotide delivery. For instance, folate receptor shows limited expression on healthy tissues, while being overexpressed, among others, on colon, lung, prostate, throat, and brain cancers [120]. Therefore, conjugation to folate has emerged as a valid option for siRNA targeting to cancer cells [111,121]. A folate-modified PEI nanocarrier successfully delivered VEGF siRNAs, resulting in a strong transfection efficiency on cells in culture, and an inhibition of tumor growth in mice (Table 1) [122].

Another example of targetable receptors is integrins. These $\alpha /$ $\beta$ heterodimers form a family of transmembrane proteins that regulate cell adhesion and migration, through interaction with extracellular matrix components such as with fibronectin and collagen [123]. Certain integrins, for example, $\alpha v \beta 3$ and $\alpha v \beta 5$, play an important role in tumor cell proliferation and migration [124], and in angiogenesis [57]. Integrin overexpression has therefore been exploited for oligonucleotide delivery, using the arginine-glycine-aspartate (RGD) peptide from fibronectin [125]. RGD-mediated targeting has successfully been used for ASO and siRNA delivery in vitro (Table 1) [126] and in vivo (Table 1) [127,128].

Another interesting and widely used targeting moiety is the triantennary GalNAc, which binds with high affinity to trimeric asialoglycoprotein receptors (ASGPRs); these lectins are strongly expressed on hepatocytes [129]. Alnylam Pharmaceuticals and Dicerna made important improvements on a series of siRNA-GalNAc conjugates, which are currently tested in preclinical and clinical trials for the treatment of liver-related pathologies, such as hepatitis B and D, hypertriglyceridemia, familial amyloidotic cardiomyopathy, and fibrotic liver diseases (Table 1) [129].

Aptamers are single-stranded oligonucleotides that can be selected on the basis of their specific binding to given receptors [130], similar to antibodies. Aptamers can be engineered, and produced by chemical synthesis [131]. High affinity, target specificity, low immunogenicity and toxicity, low production costs, and reproducibility from batch to batch qualify aptamers as promising targeting ligands for oligonucleotide delivery. Aptamers-siRNA chimeras have been used to target antiapoptotic genes in prostate cancer cells expressing PSMA receptors (Table 1) [132]. Furthermore, an aptamer specific for PSMA receptor was generated and conjugated to therapeutic siRNAs against PLK1 and BCL2, two survival genes that are overexpressed in most human tumors. Silencing of the targeted genes resulted in decreased proliferation, induced apoptosis in vitro, and tumor regression in xenograft models of prostate cancer [132]. Another aptamer was developed for specific recognition of HIV-1 envelope protein (gp120) (Table 1) [133]. This aptamer was linked to siRNA-targeting proteins that regulate HIV replication. Interestingly, the aptamer itself already provided potent antiviral activity in humanized mice, which was further enhanced when coupled to siRNAs.

\section{Endosomal Escape}

Upon binding to the cell surface, oligonucleotide carriers are internalized by one of the multiple endocytosis processes. Clathrin-dependent and independent micropinocytosis and macropinocytosis have been reported to be implicated, to different extents, in oligonucleotide uptake into cells [57]. Moreover, targeting siRNAs or ASOs to specific cell surface receptors remarkably impacts the initial internalization pathway and the subsequent intracellular trafficking [134]. 
Another crucial aspect to achieve RNAi machinery activation is the process of endosomal escape [135]. Indeed, despite significant achievements in vector development, most internalized oligonucleotides accumulate in the endocytic pathway, and only very few molecules reach the cytosol, where the RISC machinery is located (Fig. 2e). In the past few years, the cellular process of endosomal escape has become a focus of interest, and its low efficiency now appears as the main obstacle for an effective use of oligonucleotides as therapeutic agents. However, even though inefficient endosomal escape is unanimously recognized as an important stumbling block, only very few technologies and strategies have been described that can efficiently promote the translocation of oligonucleotides from endosomes to the cytosol.

\section{Enhancing endosomal escape}

The most common approaches rely on the use of endosomolytic agents that either are natural products, or deliberately designed and produced by chemical synthesis [136].

Fusogenic peptides, proteins, and lipids. Naturally evolved membrane translocation mechanisms have attracted the attention of many researchers in the delivery field [137-139]. The identification and full understanding of mechanisms used by viruses, bacteria, or toxins to escape from endosomes to the cytosol has become an intense field of investigation for the development of oligonucleotide delivery agents.

Peptides that perturb endosomal and/or lysosomal membranes, referred to as fusogenic or endosomolytic peptides, have been used to develop delivery systems for antibodies [140], proteins [141], siRNAs [142], and LNPs [143,144]. For instance, synthetic HA2 domain derivatives of hemagglutinin from influenza virus have been used for siRNA delivery [145]. In the slightly acid $\mathrm{pH}$ of endosomes, $\mathrm{HA} 2$ domain residues are protonated, upon which the anionic hydrophilic coil of HA2 undergoes a conformational rearrangement into a hydrophobic helix that destabilizes endosomal membranes [145,146].

The translocation domain ( $\mathrm{T}$ domain) of diphtheria toxin is another well-studied fusogenic peptide. Diphtheria toxin is an exotoxin secreted by Corynebacterium diphtheria. It exploits the $\mathrm{pH}$-dependent conformational change of its $\mathrm{T}$ domain to cross the endosomal membrane and to mediate the cytosolic translocation of the catalytic domain [147]. The T domain was incorporated into PEI polymer complexes for improved plasmid DNA delivery [148]. The conjugation resulted in a significant enhancement of transfection efficiency, when compared with unconjugated PEI complex. This observation also suggests that the proton sponge effect, which was mentioned earlier in the context of PEI polymers, has probably only a small impact on endosomal escape.

Following a specifically designed synthetic approach, short sequences of hydrophobic amino acids, referred as endosomal escape domains (EEDs), were identified that, when conjugated to CPPs, strongly enhanced the cytosol arrival of peptidic biomolecules. Improved endosomal escape most likely results from a high dose of EEDs that locally insert into endosomal membranes, thereby affecting membrane integrity, leading to the cytosolic release of the payload [149].

Incorporation of fusogenic lipids, such as DOPE and DOTAP, into LNPs and liposomes has also been used to improve endosomal release of encapsulated nucleic acids $[150,151]$. Incorporation of DOPA into targeted lipopolyplexes for plasmid DNA delivery afforded greater transfection efficiency, both on cells in culture and in murine models, when compared with lipopolyplexes without such lipids [152]. The improved cytosolic translocation of the genetic cargo has been attributed to the tendency of DOPE to adopt an inverted hexagonal phase structure, which represents a nonbilayer lipid organization that is thought to destabilize endosomal membranes [153].

Endosomolytic polymers. Endosomal acidification has also been exploited for the development of endosomolytic polymers. In this case, the slightly acidic $\mathrm{pH}$ of endosomes is used to induce the gradual protonation of anionic groups distributed along polymer chains. The resulting hydrophilicto-hydrophobic change facilitates polymer partitioning into endosome membranes, leading to their destabilization. For instance, copolymers were developed that consist of positively charged dimethylaminoethyl methacrylate (DMAEMA) to condense siRNAs, and an endosomal release block made of DMAEMA, propylacrylic acid, and hydrophobic butyl methacrylate residues [154]. Endosomal protonation of propylacrylic acid groups causes polymer rearrangement into a hydrophobic polycation that is capable of disrupting endosomal membranes by interfering with lipid packing.

Small molecules. Chloroquine [135] and other small molecules, identified by high-throughput screening [155-157], have been used in vitro to promote cytosolic translocation of endocytosed nucleotides and other biomolecules. However, these small molecules have a general effect on endosomes, and are not selectively at sites of internalized cargoes, and therefore result in significant toxicity. Photosensitive molecules are another class of small compounds that are successfully used to enhance the translocation of siRNAs from the endosomal to the cytosolic compartment $[158,159]$. Photosensitizers for endosomal escape are amphiphilic compounds that once internalized mainly localize in endosomes where, upon light stimulation, they generate highly reactive singlet oxygen. Reactive oxygen species affect endosomal membrane integrity and trigger the cytosolic release of the endosomal content. The localized production of damaging species and their short halftime guarantee a local effect without altering other cellular functions [160].

Although these strategies enhance the cytosolic translocation of RNA-based therapeutics, most internalized molecules still remain trapped into endosomes until being degraded. Estimates indicate that only $0.1 \%-2 \%$ of endocytosed biomolecules escape to the cytosol before other intracellular pathways, such as recycling to plasma membrane or fusion with lysosome occurs and prevents further endosomal escape. It is also worth mentioning that endosomal escape varies between cell types. For instance, endosomal escape is more prominent in antigen-presenting cells (APCs), when compared with other cell types. APCs naturally transfer exogenous antigens to the cytosol where they are processed by proteasomes, loaded onto major histocompatibility complex class-I (MHC-I) molecules in the endoplasmic reticulum, and subsequently crosspresented at cell surface. As an example, TAT-conjugated proteins are efficiently taken up by various cell lines, but only in the case of dendritic cell a cytosolic distribution of the endocytosed carriers could be observed 
[161]. Similarly, it was also demonstrated that endosomal escape of a lectin-saporin conjugate was more efficient in APCs than in cancer cell lines [162]. The reasons underlying efficient endosomal escape in APCs are still not understood at this stage. One might invoke the existence either of a dedicated protein machinery, or of a particular lipid composition that would make endosomes of APCs leakier.

\section{Quantification of cytosolic arrival}

It has been reported that 2,000-10,000 molecules of cytosolic siRNAs per cell are needed to achieve maximal depletion efficiency [163,164]. Therefore, keeping in mind that only $0.1 \%-2 \%$ of cargoes actually reach the cytosol, it is evident that the number of molecules that need to be endocytosed is strikingly high. For instance, even if 1 million receptors were available at plasma membrane for oligonucleotide targeting onto a given cell, a synchronized saturation of all available binding sites and their concomitant internalization would be needed to afford the endosomal levels that would possibly lead to cytosolic amounts compatible with a robust interference effect. This ideal situation is unlikely to be met in the complex tissue environment in which target cells are localized within living organisms, and it is thereby obvious that efficient endosomal escape technologies could tremendously impact the development of oligonucleotide therapeutics. One of the reasons for slow progress in developing efficient strategies to foster endosomal escape resides in the difficulty to quantify the cytosolic translocation of biomedical cargoes. To this end, several approaches have been proposed, based on fluorescence microscopy, subcellular fractionation, or $\mathrm{pH}$-sensitive probes [165].

Measurement of cell- and organelle-associated fluorescence is surely a fast and straightforward method. However, the differentiation between organelle-associated and cytosolic signals can only be achieved if massive amounts of marker are found in the cytosol, which is almost never the case.

Another method is based on the use of fluorescence correlation spectroscopy (FCS) [166]. FCS is a powerful analytical tool that allows to measure very small numbers of fluorescent molecules in tiny volumes (femtoliter), providing concentration values in the picomolar range. This method can be used to reliably measure the total number of internalized molecules per cell. For the quantification of the cytosolic fraction, cells must be homogenized, cytosol isolated by ultracentrifugation, and then analyzed by FCS. Such procedure is prone to experimental artefacts, however, especially when, upon translocation, the oligonucleotide delivery tool remains associated with the cytosolic leaflet of endosomes.

A biotin ligase-based assay also allows to measure the cytosolic arrival of biological therapeutics. For this, the prokaryotic biotinylation enzyme BirA is expressed in the cytosol of a eukaryotic target cell of choice. A short peptide sequence, the avi tag, is fused to a cargo whose translocation to the cytosol is to be analyzed. Upon arrival in the cytosolic compartment, the avi tag is biotinylated by the BirA enzyme. After cell lysis, cargo biotinylation is detected and quantified by western blotting, using fluorescent streptavidin or antibiotin antibodies. The former is more sensitive, but produces significant background levels, whereas the latter in less sensitive, but with less background noise [167]. In both cases, the need for western analysis renders the method cumbersome, and the background levels make the detection of small amounts of translocated materials very difficult.

The split-complementation endosomal escape assay allows direct visualization of cytosolic delivery of biomolecules at biological relevant concentrations [168]. The success of this robust assay, used to measure endosomal escape rates and to screen endosomolytic agents [149], resides in its low background values and adaptability to stable or transient cellular expression. The assay exploits the superfolder GFP protein [169]. The removal of 16 amino acids, the GFP $\beta 11$ fragment, from the N-terminus of superfolder GFP leads to a nonfluorescent soluble protein, referred to as large GFP fragment. However, when a synthetic GFP $\beta 11$ fragment binds onto the large GFP fragment, the superfolder GFP is reconstituted and its fluorescence is restored. The GFP $\beta 11$ fragment is not fluorescent alone, and it is too big to enter cells spontaneously. It can therefore be coupled onto delivery vectors to detect their cytosolic translocation. The 1:1 ratio of both fragments that is needed to reconstitute superfolder GFP allows a direct correlation between numbers of translocated GFP $\beta 11$ and fluorescence intensity.

Besides these approaches that aim at a true quantification of absolute levels of cytosolic materials, different comparative assays have also been developed, as reviewed by Martens et al. [170]. Probes that are sensitive to $\mathrm{pH}$ or to reducing environments have been synthesized [171]. For instance, naphthofluorescein is a pH-sensitive dye that changes its fluorescence intensity when translocating from the slightly acidic $\mathrm{pH}$ of endosome to the neutral cytosolic $\mathrm{pH}$ [172].

Certain toxins exert their cytotoxic activity specifically in the cytosolic compartment. For instance, pseudomonas exotoxin [173,174], alpha-sarcin, and saporin [140,162], once in the cytosol, lead to protein biosynthesis inhibition. Combinations of these toxins with vectors or endosomolytic agents have been used to monitor arrival in the cytosol. Indeed, evaluation of protein biosynthesis levels, using radiolabeled amino acids, such as $\left[{ }^{3} \mathrm{H}\right]$-leucine or $\left[{ }^{35} \mathrm{~S}\right]$-methionine, is used as an indicator of the presence of the toxin in the cytosolic compartment.

Beta-lactamase and Cre-recombinase are alternatives to these toxins. Beta-lactamase catalyzes the cleavage of a cephalosporin-derived fluorescence reporter that specifically accumulates in the cytosol of target cells. Hence, betalactamase is a valid tool to assess membrane translocation of vectors to which the enzyme is coupled [162]. Cre-recombinase is another enzyme that, upon reaching the cytosol, catalyzes the expression of a reporter protein, which is often the enhanced green fluorescent protein (eGFP). Cre-recombinase has been used in conjugation with CPPs [141] and antibodies [140].

Another method exploits the activation of a cytosolic glucocorticoid receptor (GR) to induce transcription of a reporter gene [175]. In such assay, any delivery vector that is tagged with glucocorticoid ligands (such as dexamethasone) induces, upon reaching the cytosol, GR activation and its nuclear translocation, leading to the expression of the reporter gene.

\section{Conclusions}

Oligonucleotide stability in biological media and their uptake into cells has been a focus of interest in medicinal chemistry. Targeted delivery of oligonucleotides allowed to improve their pharmacokinetics, and to reduce off-target 
effects. However, to promote RNAi-based therapies for a wide range of gene-related diseases, other problems have to be overcome. Notably, it is essential to fully understand mechanisms underlying endosomal escape. For this, the availability of universal, reliable, and robust assays to quantitatively measure arrival in the cytosol is a key condition. We expect that a molecular understanding of endosomal escape will lead to the development of enabling technologies to boost membrane translocation and cytosolic arrival of oligonucleotide therapeutics. In the meantime, RNA-based drug candidates are already in the clinics in favorable indications. GalNac-siRNA conjugates are probably the closest to entering the market [129]. Their success in the liver is due to a unique combination of favorable elements. First, high perfusion of the liver and advantageous tissue structure allows for rapid cellular uptake, and subsequent renal excretion of this conjugates is poor. Second, ASGPR expression in hepatocytes is high, and its turnover at the plasma membrane is very dynamic. Even with an endosomal escape rate of $<0.1 \%$, the number of cytosolic siRNAs that is required for an efficient interference effect is reached within a day [3]. The exact mechanisms by which these GalNAc-dependent delivery systems reach the RNAi machinery remain unknown, and at the moment, a comparable situation at extrahepatic sites has not been reported. However, with increasing numbers of oligonucleotide-based therapeutics that enter clinical trials, and the recognition of endosomal escape as being the most limiting aspect for their success, a substantial intellectual and financial investment can be expected that likely will lead to ground-breaking new discoveries.

\section{Acknowledgments}

Work in the Johannes team in the context of the theme of the current review is supported by a fellowship from Marie Sklodowska-Curie Innovative Training Network (ITN) ProteinConjugates, and grants from the Agence Nationale pour la Recherche (ANR-14-CE16-0004-03, ANR-14-CE14-0002-02, ANR-16-CE23-0005-02, ANR-16-CE23-0005-02), Human Frontier Science Program grant (RGP0029-2014), European Research Council (advanced grant 340485), and the Swedish Research Council. The Johannes team is member of Labex CelTisPhyBio (11-LBX-0038) and Idex Paris Sciences et Lettres (ANR-10-IDEX-0001-02 PSL).

\section{Author Disclosure Statement}

No competing financial interests exist

\section{References}

1. Castanotto D and JJ Rossi. (2009). The promises and pitfalls of RNA-interference-based therapeutics. Nature 457:426-433.

2. Prakash TP, MJ Graham, J Yu, R Carty, A Low, A Chappell, K Schmidt, C Zhao, M Aghajan, et al. (2014). Targeted delivery of antisense oligonucleotides to hepatocytes using triantennary $\mathrm{N}$-acetyl galactosamine improves potency 10-fold in mice. Nucleic Acids Res 42: 8796-8807.

3. Dowdy SF. (2017). Overcoming cellular barriers for RNA therapeutics. Nat Biotechnol 35:222-229.

4. Chakraborty C, AR Sharma, G Sharma, CGP Doss and SS Lee. (2017). Therapeutic miRNA and siRNA: moving from bench to clinic as next generation medicine. Mol Ther Nucleic Acids 8:132-143.

5. Ohrt T, J Muetze, P Svoboda and P Schwille. (2012). Intracellular localization and routing of miRNA and RNAi pathway components. Curr Top Med Chem 12:79-88.

6. Yang N, NR Ekanem, CA Sakyi and SD Ray. (2015). Hepatocellular carcinoma and microRNA: new perspectives on therapeutics and diagnostics. Adv Drug Deliv Rev 81:62-74.

7. Brengues M, D Teixeira and R Parker. (2005). Movement of eukaryotic mRNAs between polysomes and cytoplasmic processing bodies. Science 310:486-489.

8. Oliveira S, G Storm and RM Schiffelers. (2006). Targeted delivery of siRNA. J Biomed Biotechnol 2006:63675.

9. Beaudet AL and L Meng. (2016). Gene-targeting pharmaceuticals for single-gene disorders. Hum Mol Genet 25: R18-R26.

10. Cerritelli SM and RJ Crouch. (2009). Ribonuclease H: the enzymes in eukaryotes. FEBS J 276:1494-1505.

11. Chi X, P Gatti and T Papoian. (2017). Safety of antisense oligonucleotide and siRNA-based therapeutics. Drug Discov Today 22:823-833.

12. El-Aneed A. (2004). An overview of current delivery systems in cancer gene therapy. J Control Release 94:1-14.

13. Yin H, KJ Kauffman and DG Anderson. (2017). Delivery technologies for genome editing. Nat Rev Drug Discov 16:387-399.

14. Ju Z and W Sun. (2017). Drug delivery vectors based on filamentous bacteriophages and phage-mimetic nanoparticles. Drug Deliv 24:1898-1908.

15. Karimi M, H Mirshekari, SM Moosavi Basri, S Bahrami, M Moghoofei and MR Hamblin. (2016). Bacteriophages and phage-inspired nanocarriers for targeted delivery of therapeutic cargos. Adv Drug Deliv Rev 106:45-62.

16. Rettig GR and MA Behlke. (2012). Progress toward in vivo use of siRNAs-II. Mol Ther 20:483-512.

17. Bennett CF and EE Swayze. (2010). RNA targeting therapeutics: molecular mechanisms of antisense oligonucleotides as a therapeutic platform. Annu Rev Pharmacol Toxicol 50: 259-293.

18. Kaczmarek JC, PS Kowalski and DG Anderson. (2017). Advances in the delivery of RNA therapeutics: from concept to clinical reality. Genome Med 9:60.

19. Eckstein F. (2000). Phosphorothioate oligodeoxynucleotides: what is their origin and what is unique about them? Antisense Nucleic Acid Drug Dev 10:117-121.

20. Stein CA and D Castanotto. (2017). FDA-approved oligonucleotide therapies in 2017. Mol Ther 25:1069-1075.

21. Crooke ST, S Wang, TA Vickers, W Shen and X Liang. (2017). Cellular uptake and trafficking of antisense oligonucleotides. Nat Biotechnol 35:230-237.

22. Stein CA, JB Hansen, J Lai, SJ Wu, A Voskresenskiy, A Høg, J Worm, M Hedtjärn, N Souleimanian, et al. (2010). Efficient gene silencing by delivery of locked nucleic acid antisense oligonucleotides, unassisted by transfection reagents. Nucleic Acids Res 38:e3.

23. Castanotto D, M Lin, C Kowolik, LA Wang, XQ Ren, HS Soifer, T Koch, BR Hansen, H Oerum, et al. (2015). A cytoplasmic pathway for gapmer antisense oligonucleotidemediated gene silencing in mammalian cells. Nucleic Acids Res 43:9350-9361.

24. Prakash TP, CR Allerson, P Dande, TA Vickers, N Sioufi, R Jarres, BF Baker, EE Swayze, RH Griffey and B Bhat. (2005). Positional effect of chemical modifications on short 
interference RNA activity in mammalian cells. J Med Chem 48:4247-4253.

25. Braasch DA, S Jensen, Y Liu, K Kaur, K Arar, MA White and DR Corey. (2003). RNA interference in mammalian cells by chemically-modified RNA. Biochemistry 42:79677975.

26. Chiu Y-L and MR Tariq. (2003). siRNA function in RNAi: a chemical modification analysis. RNA 9:10341048.

27. Juliano RL. (2016). The delivery of therapeutic oligonucleotides. Nucleic Acids Res 44:6518-6548.

28. Tatiparti K, S Sau, SK Kashaw and AK Iyer. (2017). siRNA delivery strategies: a comprehensive review of recent developments. Nanomaterials 7:1-17.

29. Amarzguioui M, T Holen, E Babaie and H Prydz. (2003). Tolerance for mutations and chemical modifications in a siRNA. Nucleic Acids Res 31:589-595.

30. Czauderna F, M Fechtner, S Dames, H Aygün, A Klippel, GJ Pronk, K Giese and J Kaufmann. (2003). Structural variations and stabilising modifications of synthetic siRNAs in mammalian cells. Nucleic Acids Res 31:27052716.

31. Ozcan G, B Ozpolat, RL Coleman, AK Sood and G Lopezberestein. (2015). Preclinical and clinical development of siRNA-based therapeutics. Adv Drug Deliv Rev 87:108-119.

32. Amarzguioui M, P Lundberg, E Cantin, J Hagstrom, MA Behlke and JJ Rossi. (2006). Rational design and in vitro and in vivo delivery of Dicer substrate siRNA. Nat Protoc 1:508-517.

33. Allerson CR, N Sioufi, R Jarres, TP Prakash, N Naik, A Berdeja, L Wanders, RH Griffey, EE Swayze and B Bhat. (2005). Fully 2 '-modified oligonucleotide duplexes with improved in vitro unmodified small interfering RNA. J Med Chem 48:901-904.

34. Hassler MR, AA Turanov, JF Alterman, RA Haraszti, H Coles, MF Osborn, D Echeverria, M Nikan, WE Salomon, et al. (2018). Comparison of partially and fully chemicallymodified siRNA in conjugate-mediated delivery in vivo. Nucleic Acids Res 46:2185-2196.

35. Fitzgerald K, S White, A Borodovsky, BR Bettencourt, A Strahs, V Clausen, P Wijngaard, JD Horton, J Taubel, et al. (2017). A highly durable RNAi therapeutic inhibitor of PCSK9. N Engl J Med 376:41-51.

36. Nair JK, JLS Willoughby, A Chan, K Charisse, MR Alam, Q Wang, M Hoekstra, P Kandasamy, AV Kel'in AV, et al. (2014). Multivalent $\mathrm{N}$-acetylgalactosamine-conjugated siRNA localizes in hepatocytes and elicits robust RNAimediated gene silencing. J Am Chem Soc 136:1695816961.

37. Mani S, S Goel, M Nesterova, RM Martin, JM Grindel, ML Rothenberg, R Zhang, G Tortora and YS Cho-Chung. (2003). Clinical studies in patients with solid tumors using a second-generation antisense oligonucleotide (GEM 231) targeted against protein kinase A type I. Ann N Y Acad Sci 1002:252-262.

38. Chi KN, E Eisenhauer, L Fazli, EC Jones, SL Goldenberg, J Powers, D Tu and ME Gleave. (2005). A phase I pharmacokinetic and pharmacodynamic study of OGX011, a 2'-methoxyethyl antisense oligonucleotide to clusterin, in patients with localized prostate cancer. J Natl Cancer Inst 97:1287-1296.

39. Sewell KLEA, RS Geary, BF Baker, JM Glover, TGK Mant, RZ Yu, JA Tami and FA Dorr. (2002). Phase I trial of ISIS 104838, a 2'-methoxyethyl modified antisense oligonucleotide targeting tumor necrosis factor-alpha. J Pharmacol Exp Ther 303:1334-1343.

40. Raal FJ, RD Santos, DJ Blom, AD Marais, MJ Charng, WC Cromwell, RH Lachmann, D Gaudet, JL Tan, et al. (2010). Mipomersen, an apolipoprotein B synthesis inhibitor, for lowering of LDL cholesterol concentrations in patients with homozygous familial hypercholesterolaemia: a randomised, double-blind, placebo-controlled trial. Lancet 375:998-1006.

41. Chiriboga CA, KJ Swoboda, BT Darras, ST Iannaccone, J Montes, DC De Vivo, DA Norris, CF Bennett and KM Bishop. (2016). Results from a phase 1 study of nusinersen (ISIS-SMN(Rx)) in children with spinal muscular atrophy. Neurology 86:890-897.

42. Jolly P, P Estrela and M Ladomery. (2016). Oligonucleotidebased systems: DNA, microRNAs, DNA/RNA aptamers. Essays Biochem 60:27-35.

43. Hagedorn PH, R Persson, ED Funder, N Albæk, SL Diemer, DJ Hansen, MR Møller, N Papargyri, H Christiansen, et al. (2018). Locked nucleic acid: modality, diversity, and drug discovery. Drug Discov Today 23:101-114.

44. Summerton J. (1999). Morpholino antisense oligomers: the case for an RNase H-independent structural type. Biochim Biophys Acta 1489:141-158.

45. Järver P, T Coursindel, SEL Andaloussi, C Godfrey, MJ Wood and MJ Gait. (2012). Peptide-mediated cell and in vivo delivery of antisense oligonucleotides and siRNA. Mol Ther Nucleic Acids 1:e27.

46. Lim KRQ, R Maruyama and T Yokota. (2017). Eteplirsen in the treatment of Duchenne muscular dystrophy. Drug Des Dev Ther 11:533-545.

47. Egholm M, O Buchardt, L Christensen, C Behrens, SM Freier, DA Driver, RH Berg, SK Kim, B Norden and PE Nielsen. (1993). PNA hybridizes to complementary oligonucleotides obeying the Watson-Crick hydrogen-bonding rules. Nature 365:566-568.

48. De Mesmaeker A, KH Altmann, A Waldner and S Wendeborn. (1995). Backbone modifications in oligonucleotides and peptide nucleic acid systems. Curr Opin Struct Biol 5:343-355.

49. Lebreton J, A Waldner, V Fritsch, RM Wolf and A De Mesmaeker. (1994). Comparison of two amides as backbone replacement of the phosphodiester linkage in oligodeoxynucleotides. Tetrahedron Lett 35:5225-5228.

50. Sanghvi YS, EE Swayze, D Peoc'h, B Bhat and S Dimock. (1997). Concept, discovery and development of MMI linkage: story of a novel linkage: for antisense constructs. Nucleosides Nucleotides 16:907-916.

51. Zhang J, JT Shaw and MD Matteucci. (1999). Synthesis and hybridization property of an oligonucleotide containing a 3 '-thioformcetal linked pentathymidylate. Bioorg Med Chem Lett 9:319-322.

52. Komarova Y and AB Malik. (2010). Regulation of endothelial permeability via paracellular and transcellular transport pathways. Annu Rev Physiol 72:463-493.

53. Sarin H. (2010). Physiologic upper limits of pore size of different blood capillary types and another perspective on the dual pore theory of microvascular permeability. J Angiogenes Res 2:14.

54. Kang L, RF Wang, P Yan, M Liu, CL Zhang, MM Yu, YG Cui and XJ Xu. (2010). Noninvasive visualization of RNA delivery with $99 \mathrm{mTc}$-radiolabeled small-interference RNA in tumor xenografts. J Nucl Med 51:978-986.

55. Zheng M, D Librizzi, A Kiliç, Y Liu, H Renz, OM Merkel and T Kissel. (2012). Enhancing in vivo circulation and 
siRNA delivery with biodegradable polyethylenimine-graftpolycaprolactone-block-poly(ethylene glycol) copolymers. Biomaterials 33:6551-6558.

56. Sehgal A, A Vaishnaw and K Fitzgerald. (2013). Liver as a target for oligonucleotide therapeutics. J Hepatol 59: 1354-1359.

57. Juliano RL, X Ming, K Carver and B Laing. (2014). Cellular uptake and intracellular trafficking of oligonucleotides: implications for oligonucleotide pharmacology. Nucleic Acid Ther 24:101-113.

58. Shukla RS, B Qin and K Cheng. (2014). Peptides used in the delivery of small noncoding RNA. Mol Pharmacol 11: 3395-3408.

59. Yogasundaram H, MS Bahniuk, HD Singh, HM Aliabadi, H Uludağ and LD Unsworth. (2012). BSA nanoparticles for siRNA delivery: coating effects on nanoparticle properties, plasma protein adsorption, and in vitro siRNA delivery. Int J Biomater 2012:584060.

60. Cavallaro G, C Sardo, EF Craparo, B Porsio and G Giammona. (2017). Polymeric nanoparticles for siRNA delivery: production and applications. Int J Pharm 525: 313-333.

61. Lee SH, YY Kang, HE Jang and H Mok. (2016). Current preclinical small interfering RNA (siRNA)-based conjugate systems for RNA therapeutics. Adv Drug Deliv Rev 104:78-92.

62. Wagner E, M Zenke, M Cotten, H Beug and ML Birnstiel. (1990). Transferrin-polycation conjugates as carriers for DNA uptake into cells. Proc Natl Acad Sci U S A 87: 3410-3414.

63. Martin ME and KG Rice. (2007). Peptide-guided gene delivery. AAPS J 9: E18-E29.

64. Kaminskas LM, BJ Boyd, P Karellas, SA Henderson, MP Giannis, GY Krippner and CJH Porter. (2007). Impact of surface derivatization of poly-L-lysine dendrimers with anionic arylsulfonate or succinate groups on intravenous pharmacokinetics and disposition. Mol Pharmacol 4:949961.

65. Lee H, JH Jeong and TG Park. (2002). PEG grafted polylysine with fusogenic peptide for gene delivery: high transfection efficiency with low cytotoxicity. J Control Release 79:283-291.

66. Balhorn R. (2007). The protamine family of sperm nuclear proteins. Genome Biol 8:227.

67. Kallen KJ, R Heidenreich, M Schnee, B Petsch, T Schlake, A Thess, P Baumhof, B Scheel, SD Koch and M Fotin-Mleczek. (2013). A novel, disruptive vaccination technology. Hum Vaccines Immunother 9:2263-2276.

68. Peer D, EJ Park, Y Morishita, CV Carman and M Shimaoka. (2008). Systemic leukocyte-directed siRNA delivery revealing cyclin D1 as an anti-inflammatory target. Science 319:627-630.

69. Shukla RS, W Tai, R Mahato, W Jin and K Cheng. (2013). Development of streptavidin-based nanocomplex for siRNA delivery. Mol Pharmacol 10:4534-4545.

70. Song E, P Zhu, S-K Lee, D Chowdhury, S Kussman, DM Dykxhoorn, Y Feng, D Palliser, DB Weiner, et al. (2005). Antibody mediated in vivo delivery of small interfering RNAs via cell-surface receptors. Nat Biotechnol 23:709717.

71. Miele L. (2006). Notch signaling. Clin Cancer Res 12: 1074-1079.

72. Su Y, L Yu, N Liu, Z Guo, G Wang, J Zheng, M Wei, H Wang, A Yang, W Qin and W Wen. (2013). PSMA spe- cific single chain antibody-mediated targeted knockdown of Notch1 inhibits human prostate cancer cell proliferation and tumor growth. Cancer Lett 338:282-291.

73. Yao Y, T Sun, S Huang, S Dou, L Lin, J Chen, J Ruan, C Mao, F Yu, et al. (2012). Targeted delivery of PLK1siRNA by $\mathrm{ScFv}$ suppresses Her2+ breast cancer growth and metastasis. Sci Transl Med 4:130ra148.

74. Peer D, P Zhu, CV Carman, J Lieberman and M Shimaoka. (2007). Selective gene silencing in activated leukocytes by targeting siRNAs to the integrin lymphocyte function-associated antigen-1. Proc Natl Acad Sci U S A 104:4095-4100.

75. Owens DR. (2011). Insulin preparations with prolonged effect. Diabetes Technol Ther 13:S5-S14.

76. Greinacher A, T Thiele and K Selleng. (2015). Reversal of anticoagulants: an overview of current developments. Thromb Haemost 113:931-942.

77. He H, J Ye, E Liu, Q Liang, Q Liu and VC Yang. (2014). Low molecular weight protamine (LMWP): a nontoxic protamine substitute and an effective cell-penetrating peptide. J Control Release 193:63-73.

78. Lee LM, LC Chang, S Wrobleski, TW Wakefield and VC Yang. (2001). Low molecular weight protamine as nontoxic heparin/low molecular weight heparin antidote (III): preliminary in vivo evaluation of efficacy and toxicity using a canine model. AAPS PharmSci 3:E19.

79. Byun Y, VK Singh and VC Yang. (1999). Low molecular weight protamine: a potential nontoxic heparin antagonist. Thromb Res 94:53-61.

80. Choi YS, JY Lee, JS Suh, YM Kwon, SJ Lee, JK Chung, DS Lee, VC Yang, CP Chung and YJ Park. (2010). The systemic delivery of siRNAs by a cell penetrating peptide, low molecular weight protamine. Biomaterials 31:14291443.

81. Ye J, E Liu, J Gong, J Wang, Y Huang, H He and VC Yang. (2017). High-yield synthesis of monomeric LMWP(CPP)siRNA covalent conjugate for effective cytosolic delivery of siRNA. Theranostics 7:2495-2508.

82. Guidotti G, L Brambilla and D Rossi. (2017). Cellpenetrating peptides: from basic research to clinics. Trends Pharmacol Sci 38:406-424.

83. Futaki S and I Nakase. (2017). Cell-surface interactions on arginine-rich cell-penetrating peptides allow for multiplex modes of internalization. Acc Chem Res 50:24492456.

84. Zahid M and PD Robbins. (2015). Cell-type specific penetrating peptides: therapeutic promises and challenges. Molecules 20:13055-13070.

85. Bartz R, H Fan, J Zhang, N Innocent, C Cherrin, SC Beck, Y Pei, A Momose, V Jadhav, et al. (2011). Effective siRNA delivery and target mRNA degradation using an amphipathic peptide to facilitate $\mathrm{pH}$-dependent endosomal escape. Biochem J 435:475-487.

86. Summerton JE. (2005). Endo-Porter: a novel reagent for safe, effective delivery of substances into cells. Ann N Y Acad Sci 1058:62-75.

87. Margus H, K Padari and M Pooga. (2012). Cell-penetrating peptides as versatile vehicles for oligonucleotide delivery. Mol Ther 20:525-533.

88. Tajik-Ahmadabad B, A Polyzos, F Separovic and F Shabanpoor. (2017). Amphiphilic lipopeptide significantly enhances uptake of charge-neutral splice switching morpholino oligonucleotide in spinal muscular atrophy patientderived fibroblasts. Int J Pharm 532:21-28. 
89. Moulton HM. (2013). In vivo delivery of morpholino oligos by cell-penetrating peptides. Curr Pharm Des 19: 2963-2969.

90. Aslesh T, R Maruyama and T Yokota. (2018). Skipping multiple exons to treat DMD-promises and challenges. Biomedicines 6:1-12.

91. Echigoya Y, A Nakamura, T Nagata, N Urasawa, KRQ Lim, N Trieu, D Panesar, M Kuraoka, HM Moulton, et al. (2017). Effects of systemic multiexon skipping with peptide-conjugated morpholinos in the heart of a dog model of Duchenne muscular dystrophy. Proc Natl Acad Sci U S A 114:4213-4218.

92. Moulton HM and JD Moulton. (2010). Morpholinos and their peptide conjugates: therapeutic promise and challenge for Duchenne muscular dystrophy. Biochim Biophys Acta 1798:2296-2303.

93. Akinc A, M Thomas, AM Klibanov and R Langer. (2005). Exploring polyethylenimine-mediated DNA transfection and the proton sponge hypothesis. J Gene Med 7:657-663.

94. Benjaminsen RV, MA Mattebjerg, JR Henriksen, SM Moghimi and TL Andresen. (2013). The possible "proton sponge" effect of polyethylenimine (PEI) does not include change in lysosomal pH. Mol Ther 21:149-157.

95. Kunath K, A VonHarpe, D Fischer, H Petersen, U Bickel, K Voigt and T Kissel. (2003). Low-molecular-weight polyethylenimine as a non-viral vector for DNA delivery: comparison of physicochemical properties, transfection efficiency and in vivo distribution with high-molecularweight polyethylenimine. J Control Release 89:113-125.

96. Arima H, K Motoyama and T Higashi. (2011). Potential use of polyamidoamine dendrimer conjugates with cyclodextrins as novel carriers for siRNA. Pharmaceuticals (Basel) 5:61-78.

97. Howard KA, UL Rahbek, X Liu, CK Damgaard, SZ Glud, M Andersen, MB Hovgaard, A Schmitz, JR Nyengaard, F Besenbacher and J Kjems. (2006). RNA interference in vitro and in vivo using a novel chitosan/siRNA nanoparticle system. Mol Ther 14:476-484.

98. Adams D, OB Suhr, PJ Dyck, WJ Litchy, RG Leahy, J Chen, J Gollob and T Coelho. (2017). Trial design and rationale for APOLLO, a phase 3, placebo-controlled study of patisiran in patients with hereditary ATTR amyloidosis with polyneuropathy. BMC Neurol 17:181.

99. Zatsepin TS, YV Kotelevtsev and V Koteliansky. (2016). Lipid nanoparticles for targeted siRNA delivery-going from bench to bedside. Int J Nanomater 11:3077-3086.

100. Lorenzer C, M Dirin, A Winkler, V Baumann and J Winkler. (2015). Going beyond the liver: progress and challenges of targeted delivery of siRNA therapeutics. J Control Release 203:1-15.

101. Xiao K, Y Li, J Luo, JS Lee, W Xiao, AM Gonik, RG Agarwal and KS Lam. (2011). The effect of surface charge on in vivo biodistribution of PEG-oligocholic acid based micellar nanoparticles. Biomaterials 32:3435-3446.

102. Otsuka H, Y Nagasaki and K Kataoka. (2012). PEGylated nanoparticles for biological and pharmaceutical applications. Adv Drug Deliv Rev 64:246-255.

103. Coelho T, D Adams, A Silva, P Lozeron, P Hawkins, T Mant, J Perez, J Chiesa, S Warrington, et al. (2013). Safety and efficacy of RNAi therapy for transthyretin amyloidosis. N Engl J Med 369:819-829.

104. Tabernero J, GI Shapiro, PM Lorusso, A Cervantes, GK Schwartz, GJ Weiss, L Paz-Ares, DC Cho, JR Infante, et al. (2013). First-in-humans trial of an RNA interference therapeutic targeting VEGF and KSP in cancer patients with liver involvement. Cancer Discov 3:406-417.

105. Wahl O, M Oswald, L Tretzel, E Herres, J Arend and T Efferth. (2011). Inhibition of tumor angiogenesis by antibodies, synthetic small molecules and natural products. Curr Med Chem 18:3136-3155.

106. Balakumar C, M Ramesh, CL Tham, SP Khathi, F Kozielski, C Srinivasulu, GA Hampannavar, N Sayyad, ME Soliman and R Karpoormath. (2017). Ligand- and structure-based in silico studies to identify kinesin spindle protein (KSP) inhibitors as potential anticancer agents. J Biomol Struct Dyn 1-77.

107. Prabhakar U, H Maeda, RK Jain, EM Sevick-Muraca, W Zamboni, OC Farokhzad, ST Barry, A Gabizon, P Grodzinski and DC Blakey. (2013). Challenges and key considerations of the enhanced permeability and retention effect for nanomedicine drug delivery in oncology. Cancer Res 73:2412-2417.

108. Titze-de-almeida R, C David and SS Titze-de-almeida. (2017). The race of 10 synthetic RNAi-based drugs to the pharmaceutical market. Pharm Res 34:1339-1363.

109. Guo P, O Coban, NM Snead, J Trebley, S Hoeprich, S Guo and Y Shu. (2010). Engineering RNA for targeted siRNA delivery and medical application. Adv Drug Deliv Rev 62:650-666.

110. Hu Q, H Li, L Wang, H Gu and C Fan. (2018). DNA nanotechnology-enabled drug delivery systems. Chem Rev [Epub ahead of print]; DOI:10.1021/acs.chemrev.7b00663.

111. Lee H, AKR Lytton-jean, Y Chen, KT Love, AI Park, ED Karagiannis, A Sehgal, W Querbes, CS Zurenko, et al. (2012). Molecularly self-assembled nucleic acid nanoparticles for targeted in vivo siRNA delivery. Nat Nanotechnol 7:389-393.

112. Haque F, F Pi, Z Zhao, S Gu, H Hu, H Yu and P Guo. (2018). RNA versatility, flexibility, and thermostability for practice in RNA nanotechnology and biomedical applications. Wiley Interdiscip Rev RNA 9:1-17.

113. Guo P. (2010). The emerging field of RNA nanotechnology. Nat Nanotechnol 5:833-842.

114. Shu Y, D Shu, F Haque and P Guo. (2013). Fabrication of pRNA nanoparticles to deliver therapeutic RNAs and bioactive compounds into tumor cells. Nat Protoc 8:1635-1659.

115. Guo S, F Huang and P Guo. (2006). Construction of folate-conjugated pRNA of bacteriophage phi29 DNA packaging motor for delivery of chimeric siRNA to nasopharyngeal carcinoma cells. Gene Ther 13:814-820.

116. Beck A, L Goetsch, C Dumontet and N Corvaïa. (2017). Strategies and challenges for the next generation of antibodydrug conjugates. Nat Rev Drug Discov 16:315-337.

117. Cuellar TL, D Barnes, C Nelson, J Tanguay, SF Yu, X Wen, SJ Scales, J Gesch, D Davis, et al. (2015). Systematic evaluation of antibody-mediated siRNA delivery using an industrial platform of THIOMAB-siRNA conjugates. Nucleic Acids Res 43:1189-1203.

118. Torchilin VP. (2005). Recent advances with liposomes as pharmaceutical carriers. Nat Rev Drug Discov 4:145-160.

119. Katakowski JA, G Mukherjee, SE Wilner, KE Maier, MT Harrison, TP DiLorenzo, M Levy and D Palliser. (2016). Delivery of siRNAs to dendritic cells using DEC205targeted lipid nanoparticles to inhibit immune responses. Mol Ther 24:146-155.

120. Hilgenbrink AR and PS Low. (2005). Folate receptormediated drug targeting: from therapeutics to diagnostics. J Pharm Sci 94:2135-2146. 
121. Dohmen C, T Fröhlich, U Lächelt, I Röhl, H-P Vornlocher, P Hadwiger and E Wagner. (2012). Defined folate-PEGsiRNA conjugates for receptor-specific gene silencing. Mol Ther Nucleic Acids 1:e7.

122. Li JM, YY Wang, W Zhang, H Su, LN Ji and ZW Mao. (2013). Low-weight polyethylenimine cross-linked 2hydroxypopyl-beta-cyclodextrin and folic acid as an efficient and nontoxic siRNA carrier for gene silencing and tumor inhibition by VEGF siRNA. Int $\mathrm{J}$ Nanomater 8: 2101-2117.

123. Shafaq-Zadah M, CS Gomes-Santos, S Bardin, P Maiuri, M Maurin, J Iranzo, A Gautreau, C Lamaze and P Caswell. (2015). Persistent cell migration and adhesion rely on retrograde transport of $\beta(1)$ integrin. Nat Cell Biol 18: 54-64.

124. Desgrosellier JS and DA Cheresh. (2010). Integrins in cancer: biological implications and therapeutic opportunities. Nat Rev Cancer 10:9-22.

125. Ikeda $Y$ and K Taira. (2006). Ligand-targeted delivery of therapeutic siRNA. Pharm Res 23:1631-1640.

126. Alam MR, V Dixit, H Kang, ZB Li, X Chen, J Trejo, M Fisher and RL Juliano. (2008). Intracellular delivery of an anionic antisense oligonucleotide via receptor-mediated endocytosis. Nucleic Acids Res 36:2764-2776.

127. Han HD, LS Mangala, JW Lee, MMK Shahzad, HS Kim, D Shen, EJ Nam, EM Mora, RL Stone, et al. (2010). Targeted gene silencing using RGD-labeled chitosan nanoparticles. Clin Cancer Res 16:3910-3922.

128. Liu X, W Wang, D Samarsky, L Liu, Q Xu, W Zhang, G Zhu, P Wu, X Zuo, et al. (2014). Tumor-targeted in vivo gene silencing via systemic delivery of cRGD-conjugated siRNA. Nucleic Acids Res 42:11805-11817.

129. Huang Y. (2017). Preclinical and clinical advances of GalNAc-decorated nucleic acid therapeutics. Mol Ther Nucleic Acids 6:116-132.

130. Kruspe S and P Giangrande. (2017). Aptamer-siRNA chimeras: discovery, progress, and future prospects. Biomedicines 5:45.

131. Ni X, M Castanares, A Mukherjee and SE Lupold. (2011). Nucleic acid aptamers: clinical applications and promising new horizons. Curr Med Chem 18:4206-4214.

132. McNamara JO, ER Andrechek, Y Wang, KD Viles, RE Rempel, E Gilboa, BA Sullenger and PH Giangrande. (2006). Cell type-specific delivery of siRNAs with aptamer-siRNA chimeras. Nat Biotechnol 24:1005-1015.

133. Neff CP, J Zhou, L Remling, J Kuruvilla, J Zhang, H Li, DD Smith, P Swiderski, JJ Rossi and R Akkina. (2011). An aptamer-siRNA chimera suppresses HIV-1 viral loads and protects from helper $\mathrm{CD} 4^{+} \mathrm{T}$ cell decline in humanized mice. Sci Transl Med 3:66ra6.

134. Juliano RL, X Ming and O Nakagawa. (2012). Cellular uptake and intracellular trafficking of antisense and siRNA oligonucleotides. Bioconjug Chem 23:147-157.

135. Varkouhi AK, M Scholte, G Storm and HJ Haisma. (2011). Endosomal escape pathways for delivery of BioLogicals. Anticancer Res 151:220-228.

136. Endoh T and T Ohtsuki. (2009). Cellular siRNA delivery using cell-penetrating peptides modified for endosomal escape. Adv Drug Deliv Rev 61:704-709.

137. Johannes L and V Popoff. (2008). Tracing the retrograde route in protein trafficking. Cell 135:1175-1187.

138. Sandvig K and B van Deurs. (2005). Delivery into cells: lessons learned from plant and bacterial toxins. Gene Ther $12: 865-872$.
139. Sodeik B. (2000). Mechanisms of viral transport in the cytoplasm. Trends Microbiol 8:465-472.

140. Akishiba M, T Takeuchi, Y Kawaguchi, K Sakamoto, HH Yu, I Nakase, T Takatani-Nakase, F Madani, A Gräslund and S Futaki. (2017). Cytosolic antibody delivery by lipidsensitive endosomolytic peptide. Nat Chem 9:751-761.

141. Wadia JS, RV Stan and SF Dowdy. (2004). Transducible TAT-HA fusogenic peptide enhances escape of TATfusion proteins after lipid raft macropinocytosis. Nat Med 10:310-315.

142. Lundberg P, S El-Andaloussi, T Sutlu, H Johansson and U Langel. (2007). Delivery of short interfering RNA using endosomolytic cell-penetrating peptides. FASEB J 21:26642671.

143. Futaki S, Y Masui, I Nakase, Y Sugiura, T Nakamura, K Kogure and H Harashima. (2005). Unique features of a $\mathrm{pH}$-sensitive fusogenic peptide that improves the transfection efficiency of cationic liposomes. J Gene Med 7: 1450-1458.

144. Ahmad A, S Ranjan, W Zhang, J Zou, I Pyykkö and PKJ Kinnunen. (2015). Novel endosomolytic peptides for enhancing gene delivery in nanoparticles. Biochim Biophys Acta 1848:544-553.

145. Oliveira S, I van Rooy, O Kranenburg, G Storm and RM Schiffelers. (2007). Fusogenic peptides enhance endosomal escape improving siRNA-induced silencing of oncogenes. Int J Pharm 331:211-214.

146. Carr CM and PS Kim. (1993). A spring-loaded mechanism for the conformational change of influenza hemagglutinin. Cell 73:823-832.

147. Ladokhin AS. (2013). pH-triggered conformational switching along the membrane insertion pathway of the diphtheria toxin T-domain. Toxins 5:1362-1380.

148. Kakimoto S, T Hamada, Y Komatsu, M Takagi, T Tanabe, H Azuma, S Shinkai and T Nagasaki. (2009). The conjugation of diphtheria toxin $\mathrm{T}$ domain to poly(ethylenimine) based vectors for enhanced endosomal escape during gene transfection. Biomaterials 30:402-408.

149. Lönn P, AD Kacsinta, X-S Cui, AS Hamil, M Kaulich, K Gogoi and SF Dowdy. (2016). Enhancing endosomal escape for intracellular delivery of macromolecular biologic therapeutics. Sci Rep 6:32301.

150. Santos RS, GR Dakwar, E Zagato, T Brans, C Figueiredo, K Raemdonck, NF Azevedo, SC De Smedt and K Braeckmans. (2017). Intracellular delivery of oligonucleotides in Helicobacter pylori by fusogenic liposomes in the presence of gastric mucus. Biomaterials 138:1-12.

151. Zuhorn IS, U Bakowsky, E Polushkin, WH Visser, MCA Stuart, JBFN Engberts and D Hoekstra. (2005). Nonbilayer phase of lipoplex-membrane mixture determines endosomal escape of genetic cargo and transfection efficiency. Mol Ther 11:801-810.

152. Du Z, MM Munye, AD Tagalakis, MDI Manunta and SL Hart. (2014). The role of the helper lipid on the DNA transfection efficiency of lipopolyplex formulations. Sci Rep 4:7107.

153. Heyes J, L Palmer, K Bremner and I MacLachlan. (2005). Cationic lipid saturation influences intracellular delivery of encapsulated nucleic acids. J Control Release 107:276287.

154. Convertine AJ, DSW Benoit, CL Duvall, AS Hoffman and PS Stayton. (2009). Development of a novel endosomolytic diblock copolymer for siRNA delivery. J Control Release 133:221-229. 
155. Yang B, X Ming, C Cao, B Laing, A Yuan, MA Porter, EA Hull-Ryde, J Maddry, M Suto, WP Janzen and RL Juliano. (2015). High-throughput screening identifies small molecules that enhance the pharmacological effects of oligonucleotides. Nucleic Acids Res 43:1987-1996.

156. Osborn MF, JF Alterman, M Nikan, H Cao, MC Didiot, MR Hassler, AH Coles and A Khvorova. (2015). Guanabenz $\left(\right.$ Wytensin $^{\mathrm{TM}}$ ) selectively enhances uptake and efficacy of hydrophobically modified siRNAs. Nucleic Acids Res 43:8664-8672.

157. Ming X, K Carver, M Fisher, R Noel, JC Cintrat, D Gillet, J Barbier, C Cao, J Bauman and RL Juliano. (2013). The small molecule Retro-1 enhances the pharmacological actions of antisense and splice switching oligonucleotides. Nucleic Acids Res 41:3673-3687.

158. Oliveira S, MM Fretz, A Høgset, G Storm and RM Schiffelers. (2007). Photochemical internalization enhances silencing of epidermal growth factor receptor through improved endosomal escape of siRNA. Biochim Biophys Acta 1768:1211-1217.

159. Shiraishi T and PE Nielsen. (2006). Photochemically enhanced cellular delivery of cell penetrating peptide-PNA conjugates. FEBS Lett 580:1451-1456.

160. Dominska M and DM Dykxhoorn. (2010). Breaking down the barriers : siRNA delivery and endosome escape. J Cell Sci 123:1183-1189.

161. Loison F, P Nizard, T Sourisseau, P Le Goff, L Debure, Y Le Drean and D Michel. (2005). A ubiquitin-based assay for the cytosolic uptake of protein transduction domains. Mol Ther 11:205-214.

162. Garcia-Castillo MD, T Tran, A Bobard, H-F Renard, SJ Rathjen, E Dransart, C Lamaze, M Lord, J-C Cintrat, et al. (2015). Retrograde transport is not required for cytosolic translocation B-subunit of Shiga toxin. J Cell Sci 128: 2373-2387.

163. Wittrup A, A Ai, X Liu, P Hamar, R Trifonova, K Charisse, M Manoharan, T Kirchhausen and J Lieberman. (2015). Visualizing lipid-formulated siRNA release from endosomes and target gene knockdown. Nat Biotechnol 33:870-876.

164. Gilleron J, W Querbes, A Zeigerer, A Borodovsky, G Marsico, U Schubert, K Manygoats, S Seifert, C Andree, et al. (2013). Image-based analysis of lipid nanoparticlemediated siRNA delivery, intracellular trafficking and endosomal escape. Nat Biotechnol 31:638-646.

165. Li M, Y Tao, Y Shu, JR Larochelle, A Steinauer, D Thompson, A Schepartz, Z Chen and DR Liu. (2015). Discovery and characterization of a peptide that enhances endosomal escape of delivered proteins in vitro and in vivo. J Am Chem Soc 137:14084-14093.

166. Rezgui R, K Blumer, G Yeoh-Tan, AJ Trexler and M Magzoub. (2016). Precise quantification of cellular uptake of cell-penetrating peptides using fluorescence-activated cell sorting and fluorescence correlation spectroscopy. Biochim Biophys Acta 1858:1499-1506.

167. Verdurmen WPR, M Mazlami and A Plückthun. (2017). A quantitative comparison of cytosolic delivery via different protein uptake systems. Sci Rep 7:13194.

168. Milech N, BA Longville, PT Cunningham, MN Scobie, HM Bogdawa, S Winslow, M Anastasas, T Connor, F Ong, et al. (2015). GFP-complementation assay to detect functional CPP and protein delivery into living cells. Sci Rep 5:18329.

169. Cabantous S, TC Terwilliger and GS Waldo. (2005). Protein tagging and detection with engineered self-assembling fragments of green fluorescent protein. Nat Biotechnol 23:102107.

170. Martens TF, K Remaut, J Demeester, SC De Smedt and K Braeckmans. (2014). Intracellular delivery of nanomaterials: how to catch endosomal escape in the act. Nano Today 9:344-364.

171. Hällbrink M, A Florén, A Elmquist, M Pooga, T Bartfai and Ü Langel. (2001). Cargo delivery kinetics of cellpenetrating peptides. Biochim Biophys Acta 1515:101109.

172. Qian Z, PG Dougherty and D Pei. (2015). Monitoring the cytosolic entry of cell-penetrating peptides using a $\mathrm{pH}$ sensitive fluorophore. Chem Commun (Camb) 51:21622165.

173. Michalska M and P Wolf. (2015). Pseudomonas exotoxin A: optimized by evolution for effective killing. Front Microbiol 6:963.

174. Seth P, DJ Fitzgerald, MC Willingham and I Pastan. (1984). Role of a low-pH environment in adenovirus enhancement of the toxicity of a Pseudomonas exotoxinepidermal growth factor conjugate. J Virol 51:650-655.

175. Yu P, B Liu and T Kodadek. (2005). A high-throughput assay for assessing the cell permeability of combinatorial libraries. Nat Biotechnol 23:746-751.

Address correspondence to:
Ludger Johannes, PhD
Institut Curie
PSL Research University
Cellular and Chemical Biology
U1143 INSERM
UMR3666 CNRS
26 rue d'Ulm
75248 Paris Cedex 05
France

E-mail: ludger.johannes@curie.fr

Received for publication December 29, 2017; accepted after revision April 12, 2018. 